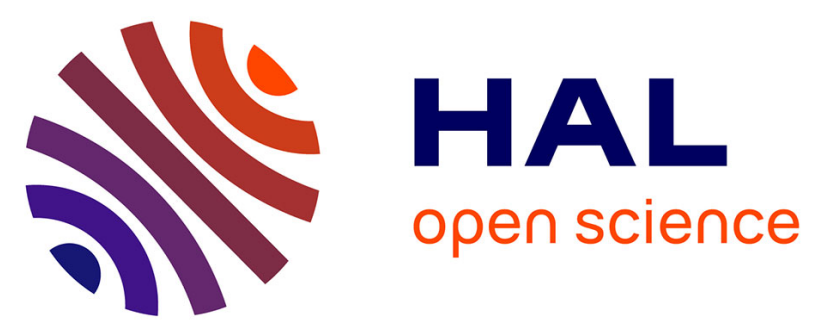

\title{
Endogenous oestradiol as a positive correlate of plasma fibrinogen among older postmenopausal women: a population-based study (the Three-City cohort study).
}

Marianne Canonico, Sylvie Brailly-Tabard, Pascale Gaussem, Julie Setiao, Olivier Rouaud, Joanne Ryan, Laure Carcaillon, Anne Guiochon-Mantel, Pierre-Yves Scarabin

\section{To cite this version:}

Marianne Canonico, Sylvie Brailly-Tabard, Pascale Gaussem, Julie Setiao, Olivier Rouaud, et al.. Endogenous oestradiol as a positive correlate of plasma fibrinogen among older postmenopausal women: a population-based study (the Three-City cohort study).. Clinical Endocrinology, 2012, 77 (6), pp.90510. 10.1111/j.1365-2265.2012.04448.x . inserm-01148069

\section{HAL Id: inserm-01148069 https://www.hal.inserm.fr/inserm-01148069}

Submitted on 4 May 2015

HAL is a multi-disciplinary open access archive for the deposit and dissemination of scientific research documents, whether they are published or not. The documents may come from teaching and research institutions in France or abroad, or from public or private research centers.
L'archive ouverte pluridisciplinaire HAL, est destinée au dépôt et à la diffusion de documents scientifiques de niveau recherche, publiés ou non, émanant des établissements d'enseignement et de recherche français ou étrangers, des laboratoires publics ou privés. 
Serum estradiol as a positive correlate of plasma fibrinogen among older postmenopausal women.

A population-based study (The Three-City cohort study)

Marianne Canonico ${ }^{1}$, Sylvie Brailly-Tabard ${ }^{2-3}$, Pascale Gaussem ${ }^{4}$, Julie Setiao ${ }^{2-3}$, Olivier Rouaud ${ }^{5}$, Joanne Ryan $^{6}$, Laure Carcaillon ${ }^{1-7}$, Anne Guiochon-Mantel ${ }^{2-3}$, Pierre-Yves Scarabin ${ }^{1}$

${ }^{1}$ Centre for Research in Epidemiology and Population Health, U1018, Hormones and Cardiovascular Disease and Univ Paris-Sud, UMR-S 1018, Villejuif, France

${ }^{2}$ Service de Génétique moléculaire, Pharmacogénétique et Hormonologie, Hôpital Bicêtre, APHP, Le Kremlin-Bicêtre, France

${ }^{3}$ Inserm UMR-S693, Univ Paris-sud, IFR Bicêtre, France

${ }^{4}$ Inserm U765, Université Paris Descartes, Sorbonne Paris Cité, APHP, Hôpital Européen Georges Pompidou, Paris, France

${ }^{5}$ CMMR CHU Dijon, Dijon, France

${ }^{6}$ Inserm Unit 1061, University Montpellier, France

${ }^{7}$ Inserm Unit U593, Victor Segalen University, Bordeaux, France

Adresse: $\quad 16$ av. Paul Vaillant Couturier 94807 Villejuif Cedex

Tel: +33145595166

Fax: $+33145595170$

Corresponding author: Marianne Canonico (marianne.canonico@inserm.fr) 
Abstract

Background. Plasma fibrinogen is a strong predictor of ischemic arterial disease in women. Sex steroid hormones including hormone therapy may play an important role in the development of cardiovascular disease. However, whether or not endogenous sex steroid hormones influence the plasma fibrinogen concentrations among postmenopausal women remains unclear.

Objectives. To investigate the association of plasma fibrinogen levels with endogenous sex steroid hormones and SHBG among postmenopausal women.

Methods. We used data from the French prospective Three-City cohort study which included 9,294 non-institutionalized men and women over 65 years. Total $17 \beta$-estradiol (E2, pg/ml), total Testosterone $(\mathrm{T}, \mathrm{ng} / \mathrm{ml})$, SHBG $(\mathrm{nmol} / \mathrm{l})$ and fibrinogen $(\mathrm{g} / \mathrm{l})$ were measured in stored plasmas in a subcohort of 602 randomly selected postmenopausal women who used neither hormone medication nor anticoagulation therapy. Multivariate linear regression models were used to estimate the regression coefficients assessed in fibrinogen unit by 1 SD increase in log-distribution of sex steroid hormones and SHBG. .

Results. E2 but neither T nor SHBG was positively associated with plasma fibrinogen levels ( $\beta=0.148$, $\mathrm{p}<0.001)$. Adjustment for cardiovascular risk factors including diabetes made no substantial change to the results $(\boldsymbol{\beta}=\mathbf{0 . 1 4 5} \mathrm{p}<0.001)$. The association of fibrinogen with E2 was stronger among women with BMI over $25 \mathrm{~kg} / \mathrm{m}^{2}$ compared to those with normal weight $(\boldsymbol{\beta}=\mathbf{0 . 1 5 6}, \mathrm{p}<0.001$ and $\boldsymbol{\beta}=\mathbf{0 . 0 9 2}, \mathrm{p}=0.02$ respectively, $\mathrm{p}$ for interaction $=0.04)$.

Conclusion. E2 emerges as a positive and independent correlate of plasma fibrinogen among postmenopausal women, especially in subjects who are overweight. These findings suggest a deleterious effect of endogenous estrogens on cardiovascular risk profile among postmenopausal women.

Key words: Fibrinogen, estradiol, testosterone, sex hormone binding globulin, postmenopausal women 


\section{Introduction}

Fibrinogen, the fibrin clot precursor, plays a central role in the haemostatic process ${ }^{1}$. Elevated plasma fibrinogen levels have been shown to be associated with established cardiovascular risk factors ${ }^{2}$. In particular, plasma fibrinogen has been positively related to age and body-mass index (BMI) ${ }^{2}$. Plasma fibrinogen has emerged as a strong predictor of arterial disease among both men and women ${ }^{3}$ and this association was recently found in a population-based study among elderly subjects ${ }^{4}$.

Sex steroid hormones including both hormone therapy and endogenous sex steroid hormones may play an important role in the development of arterial disease. Despite compelling evidence for a cardioprotective effect of estrogens, randomized clinical trials have reported an increased risk of coronary heart disease among old women using hormone therapy as compared to non users ${ }^{5}$. In addition, it is now well demonstrated that hormone therapy increases the risk of stroke among postmenopausal women ${ }^{6,7}$. By contrast, little is known on the association of endogenous sex steroid hormones with cardiovascular disease and results remain non significant ${ }^{8-10}$.

The relationship between sex steroid hormones and plasma fibrinogen has been studied in some different contexts and results are conflicting. It has been shown that postmenopausal hormone therapy slightly affects fibrinogen levels ${ }^{11}$ while the association of fibrinogen with endogenous sex steroid hormones among peri/postmenopausal women led to inconclusive results ${ }^{12-15}$. Nevertheless, an increase in plasma fibrinogen concentrations has been consistently observed during pregnancy, suggesting a positive and strong correlation between levels of circulating endogenous estrogens and plasma fibrinogen among young women ${ }^{16-22}$. In this context, we hypothesized that plasma levels of endogenous estradiol could be positively related to plasma fibrinogen levels. Therefore, we investigated the association of fibrinogen with total estradiol (E2), total testosterone (T) and Sex Hormone Binding Globulin (SHBG) among postmenopausal women included in the Three-City (3C) study, a large community based prospective cohort study. 


\section{Methods}

\section{Study population}

This study is part of the 3C study, a large ongoing French prospective cohort which aimed to evaluate the risk of dementia attributable to vascular disorders. The study protocol was approved by the Ethics Committee of the University Hospital of Kremlin-Bicêtre and each participant signed a written informed consent. A detailed methodology of the study has been previously described ${ }^{23}$. Briefly, 3,649 men and 5,645 women over 65 years registered on electoral rolls and not institutionalized were recruited in three French cities (Bordeaux, Dijon and Montpellier) between 1999 and 2001. Baseline data were collected by trained psychologists or nurses during a face to face interview using standardized questionnaires at home or at the study center. These data included information on sociodemographic characteristics, education, medical history, medication use, food consumption and alcohol and tobacco use. Systolic and diastolic blood pressure, weight and height were assessed during a physical examination.

Recently, a case-cohort study has been set-up from the $3 \mathrm{C}$ study to investigate the association of biological parameters with cardiovascular and dementia risk. In practice, the population study consists of a random subsample of the original cohort (the subcohort) and all the incident cases outside the subcohort. The methodology has been described in detail ${ }^{24}$. The present analysis focused on women included in the subcohort $(n=759)$. After exclusion of women who used hormone medication $(n=120)$ or anticoagulation therapy $(n=18)$ and subjects with a missing value regarding the fibrinogen measurement $(n=19)$, this left 602 postmenopausal women.

\section{Baseline covariates}

Smoking status was studied in three categories (never, past, current). Body mass index (BMI) was calculated by dividing the weight by height in meters squared and overweight was defined as BMI superior or equal to $25 \mathrm{~kg} / \mathrm{m}^{2}$. Glycemia status was considered as "diabetes" if the fasting glycemia value at inclusion was superior or equal 
to $1.26 \mathrm{~g} / \mathrm{L}(7.00 \mathrm{mmol} / \mathrm{L})$ and/or a treatment for diabetes, "high glycemia" if the value was between 1.10 and $1.26 \mathrm{~g} / \mathrm{L}(6.10$ and $7.00 \mathrm{mmol} / \mathrm{L})$ and "normal glycemia" if glycemia was inferior to $1.10 \mathrm{~g} / \mathrm{L}(6.10 \mathrm{mmol} / \mathrm{L})$. Hypertension status was defined as high blood pressure measurement (systolic blood pressure superior or equal to $140 \mathbf{~ m m}$ Hg and/or diastolic blood pressure superior or equal to $90 \mathrm{~mm} \mathrm{Hg}$ ) and/or an antihypertensive therapy at baseline. Hypercholesterolemia was considered present if the level of cholesterol was superior to $2.40 \mathrm{~g} / \mathrm{L}$ at baseline and/or the subject was treated for hypercholesterolemia.

\section{Blood collection and biological measurements}

At baseline, fasting blood sample were collected for $90 \%$ of the entire cohort, including all the subjects selected for the case/cohort study. Citrated and EDTA plasmas were obtained after one centrifugation at $3.000 \mathrm{~g}$ and immediately stored at $-80^{\circ} \mathrm{C}$ in 500 microliters and 1 milliliter plastic tubes respectively.

Fibrinogen was centrally measured in citrated plasmas using the kinetic method of Clauss (Dade Behring) with a minimum detectable concentration (MDC) of $0.2 \mathrm{~g} / \mathrm{l}$. The intraassay and interassay coefficient of variation $(\mathrm{CV})$ were $0.97 \%$ and $2.6 \%$ respectively for a fibrinogen concentration of 2.69 g/l. Data on fibrinogen measurement were missing for 19 women recruited in Bordeaux. These subjects did not differ from the other ones in term of age and traditional cardiovascular risk factors.

Total E2, total T and SHBG were centrally measured in EDTA plasmas. Plasma total E2 was measured with a sensitive direct radioimmunoassay (RIA) on an Orion Diagnostica device (Spectria, Espoo, Finland) with a MDC of $2 \mathrm{pg} / \mathrm{ml}(7.3 \mathrm{pmol} / \mathrm{l})$ that was arbitrarily assigned to the 38 subjects with no detectable estradiol concentration. The intraassay and interassay coefficients of variation (CV) were $17.6 \%$ and $18.1 \%$ for a total estradiol concentration of $3.2 \mathrm{pg} / \mathrm{mL}(12 \mathrm{pmol} / \mathrm{L})$, respectively and $2.8 \%$ and $5.8 \%$ for a total estradiol concentration of $24 \mathrm{pg} / \mathrm{mL}$ ( $88 \mathrm{pmol} / \mathrm{L})$, respectively. 
Plasma total T was measured by the same direct RIA as did total E2. The MDC was $0.02 \mathrm{ng} / \mathrm{ml}(0.06$ $\mathrm{nmol} / \mathrm{l}$ ) and the intraassay and interassay $\mathrm{CV}$ were $7.5 \%$ and $7.0 \%$ respectively for a total $\mathrm{T}$ concentration of $0.46 \mathrm{ng} / \mathrm{ml}$ and $0.35 \mathrm{ng} / \mathrm{ml}$ respectively $(1.6 \mathrm{nmol} / 1$ and $1.2 \mathrm{nmol} / \mathrm{l}$, respectively). Plasma SHBG was measured with a solid-phase chemiluminescent immunometric assay (Immulite ${ }^{\circledR}$, Siemens Health Diagnostic Products, Caernarfon, Llanberis, UK) with a MDC of $0.02 \mathrm{nmol} / \mathrm{l}$. The intraassay and interassay CV were respectively $3.2 \%$ and $4.6 \%$ for a SHBG concentration of $56 \mathrm{nmol} / \mathrm{l}$ 25 .

\section{Statistical analysis and covariates}

Baseline characteristics of subjects are presented as absolute numbers and percentages for categorical variables and arithmetic means and standard deviations (SD) for normal continuous variables. Variables which presented a positively skewed distribution were log-transformed and values were expressed as geometric means (GM) and interquartile range (IQR) as recommended ${ }^{\mathbf{2 6}}$. Linear regression analyses were used to test the association of fibrinogen with E2, T and SHBG. Regression coefficients were assessed in fibrinogen unit by $1 \mathrm{SD}$ increase in the log-distribution of sex steroid hormones and SHBG. First adjustment included center, age, , hypercholesterolemia, glycemia status, hypertension and smoking status. Models were further adjusted for other sex steroid hormones and SHBG (adjustment 2). Using a multiplicative linear model, an interaction of BMI with E2 on plasma fibrinogen was detected. Therefore, linear regression of fibrinogen on E2 was separately performed among women with BMI less than $25 \mathrm{~kg} / \mathrm{m}^{2}$ and among women with an overweight. Then, to assess the independence of the correlation between fibrinogen and E2, final adjustment within each stratum further included BMI as a continuous variable. In addition, means of plasma fibrinogen were assessed by tertile of the E2 distribution in each stratum. Tests for linear trend across the three categories of sex steroid hormone were used to assess the significance of the variables in the models after having verified the linearity of the associations. To assess the linearity of the relation between E2and plasma fibrinogen levels, we used tests based on the difference in the log-likelihood between 2 models of prediction (one with 2 dummy variables corresponding to the tertile of the 
parameter distribution and the other including the qualitative ordinal variable in 3 categories). All tests were not significant, and thus we did not reject the hypothesis of linearity.

Statistical analyses were performed with the Statistical Analysis System software, version 9.2 (SAS Institute, Inc., Cary, NC). 


\section{Results}

\section{Baseline characteristics of the subjects}

Baseline characteristics of the study population are presented in table 1 . The final sample included 602 women, aged 74.8 years $(\mathrm{SD}=5.5)$ on average. Regarding cardiovascular risk factors, $7.7 \%$ of women suffered from diabetes, $77.6 \%$ from hypertension, $63.5 \%$ from hypercholesterolemia and $48.2 \%$ were overweight. In addition, 84 (13.9\%) subjects had a prevalent disorder. The mean fibrinogen level was $3.42 \mathrm{~g} / \mathrm{l}$ and GM of total E2, total $\mathrm{T}$ and SHBG were $5.29 \mathrm{pg} / \mathrm{ml}, 0.28 \mathrm{ng} / \mathrm{ml}$ and $26.3 \mathrm{nmol} / \mathrm{l}$, respectively.

\section{Associations of plasma fibrinogen levels with sex steroid hormones and SHBG}

Association of fibrinogen with log-transformed total E2, total T and SHBG are given in the table 2. In univariate analysis, plasma fibrinogen levels were positively and significantly correlated to total E2 ( $\beta \square$ of fibrinogen unit in $\mathrm{g} / \mathrm{l}$ by $1 \mathrm{SD}$ increase of total $\mathrm{E} 2 \mathrm{in} \mathrm{pg} / \mathrm{ml}=0.148, \mathrm{p}<0.001$ ). Adjustment for center and traditional cardiovascular risk factors including diabetes did not substantially change the result ( $\beta \square$ of fibrinogen unit in $\mathrm{g} / \mathrm{l}$ by $1 \mathrm{SD}$ increase of total $\mathrm{E} 2$ in $\mathrm{pg} / \mathrm{ml}=0.145, \mathrm{p}<0.001$ ). In addition, further adjustment for Total T and SHBG neither modify this association ( $\beta$ of fibrinogen unit in $\mathrm{g} / \mathrm{l}$ by $1 \mathrm{SD}$ increase of total $\mathrm{E} 2$ in $\mathrm{pg} / \mathrm{ml}=0.147, \mathrm{p}<0.001)$.

With respect to $T$ and SHBG, neither crude nor adjusted analysis showed a significant association with plasma fibrinogen. Furthermore, adding BMI in the full models did not change the results $(\beta$ of fibrinogen unit in $\mathrm{g} / \mathrm{l}$ by $1 \mathrm{SD}$ increase of total $\mathrm{T}$ in $\mathrm{ng} / \mathrm{ml}=0.015, \mathrm{p}=0.59$ and $\beta$ of fibrinogen unit in $\mathrm{g} / \mathrm{l}$ by $1 \mathrm{SD}$ increase of total $\mathrm{SHBG}$ in $\mathrm{nmol} / \mathrm{l}=-\mathbf{0 . 0 1 1}, \mathrm{p}=0.73$ ).

There was a significant interaction of total E2 with being overweight on plasma fibrinogen levels (figure 1). In a fully adjusted model including BMI, the association between total E2 and fibrinogen was of borderline significant for lean women while it was stronger for subjects who presented an overweight $\beta \square$ of fibrinogen unit in $\mathrm{g} / \mathrm{l}$ by 1 SD increase of total $\mathrm{E} 2$ in $\mathrm{pg} / \mathrm{ml}=\mathbf{0 . 0 9 2}, \mathbf{p}=\mathbf{0 . 0 2}$ and $\beta \square$ of fibrinogen unit in $\mathrm{g} / \mathrm{l}$ by $1 \mathrm{SD}$ increase of total $\mathrm{E} 2$ in $\mathrm{pg} / \mathrm{ml}=\mathbf{0 . 1 5 6}, \mathrm{p}<0.001$, respectively, $\mathrm{p}$ for 
interaction=0.04). Overweight women belonging to the third tertile of total E2 had an approximate $15 \%$ increase in plasma fibrinogen concentrations compared to lean women with low total E2 levels.

Stratified analyses showed no striking difference in the association of fibrinogen with sex steroid hormones and SHBG according to cardiovascular risk factors, including diabetes, hypercholesterolemia, hypertension and smoking. 


\section{Discussion}

To our knowledge, this is the first population-based study to show a positive and independent association of endogenous E2 with plasma fibrinogen among postmenopausal women who used neither hormone medication nor anticoagulation therapy. This association was significantly more pronounced among women who were overweight compared to lean ones. By contrast, neither $\mathrm{T}$ nor SHBG were associated with plasma fibrinogen levels.

The association of plasma fibrinogen levels with endogenous E2 among peri/postmenopausal women was only investigated in two studies ${ }^{12,14}$. On one hand, Sowers et al. used the data of the Study of Women's Health Across the Nation (SWAN) to describe the joint changes in haemostatic parameters and hormones concentrations among women transitioning to menopause ${ }^{14}$. Results showed that changes in endogenous E2 during the menopausal transition were not associated with plasma fibrinogen variations. Although this study did not provide direct information on the association of endogenous estradiol with plasma fibrinogen among postmenopausal women, these data did not suggest that variation in endogenous sex steroid hormones could induce changes in plasma levels of fibrinogen. However, women included in the SWAN study were younger than the $3 \mathrm{C}$ Study participants and this difference in age between the two studies could in part explain this discrepancy. On the other hand, Folsom et al. investigated the association between endogenous sex steroid hormones and fibrinogen among postmenopausal women recruited in the Atherosclerosis Risk In Communities (ARIC) study ${ }^{12}$. In this study, estrogen was positively associated with plasma fibrinogen and our results are concordant with these previous findings.

With respect to total $\mathrm{T}$ and SHBG, our findings showing no relationship with plasma fibrinogen are concordant with the results from three studies which consistently found no association of fibrinogen with total T and SHBG ${ }^{12,13,15}$.

Several biological mechanisms could explain the positive association of endogenous E2 with plasma fibrinogen. Fibrinogen is strongly implicated in coagulation processing but is also a systemic 
inflammation marker. The mechanisms underlying the increase in plasma levels of fibrinogen jointly with an elevated concentration of circulating E2 might include both procoagulant and proinflammatory properties of endogenous E2. As observed in physiological models of hyperestrogeny such as pregnancy or ovarian stimulation, important increases in circulating E2 leads to a dramatically rise in procoagulant factors including fibrinogen and a decrease in fibrinolytic activity $16,18-21,27,28$. In addition, experimental studies in pregnant animals showed an up-regulation of liver fibrinogen biosynthesis by circulating E2 ${ }^{29}$. With respect to inflammatory processing, endogenous E2 has been shown to be positively and significantly associated with plasma levels of C-reactive protein among postmenopausal women ${ }^{30,31}$. These findings suggest that high levels of endogenous E2 could induce both a procoagulant and a proinflammatory state in postmenopausal women.

Adipose tissue might play a role in modifying the association of fibrinogen with circulating E2. Obesity is characterized by a deleterious haemostatic profile and a low grade inflammation state which can result from both a direct and an indirect processing. On one hand, adipocyte hypertrophy and hyperplasia directly result in a secretion of adipokines which are implicated in both production of proinflammatory proteins and induce a hypofribrinolys and prothrombotic state ${ }^{32,33}$. On the other hand, an inflammation state in obese subjects can indirectly result from the increase in testosterone aromatization to product E2 which has inflammatory and procoagulant properties ${ }^{34}$. The direct mechanism seems to be predominant in the deleterious haemostatic profile and the low grade inflammation state of obese subjects as showed by our data where the positive correlation between BMI and fibrinogen $(r=0.18, p<0.001)$ remained significant after adjustment for total $\mathrm{E} 2(\mathrm{r}=0.14$, $\mathrm{p}<0.001)$. Since haemostasis and inflammation are closely linked in the context of atherosclerosis, it is conceivable to hypothesize that E2 could interact with inflammatory and procoagulant factors directly secreted by adipose tissue to increase the plasma fibrinogen, the levels of which are enhanced in atherosclerosis ${ }^{35}$.

Our study presented strengths and limitations including the study design, the biological measurements and the potential confounders in the statistical analysis. 
First, this analysis was carried out on an important number of subjects randomly selected from a population-based cohort study. In addition, baseline data were collected by standardized questionnaires during a face-to-face interview. However, the cross-sectional study design might not be adequate to determine whether changes in plasma fibrinogen levels were a consequence of E2 variations or the reverse.

With respect to the sex steroid hormones assays, especially at low levels of estradiol in postmenopausal women, conventional RIAs with preceding purification steps would provide more reliable and accurate measurements of plasma estradiol as compared with direct RIA ${ }^{36}$. However, measurement error related to direct RIA would bias our analysis towards the null hypothesis, resulting in a potential underestimation of the true associations.

Finally, we could not exclude the fact that other confounders could explain our findings of an association between total E2 and plasma fibrinogen. However, adjustment for several cardiovascular risk factors did not change the results.

In conclusion, our results show a positive and independent association of total E2 with plasma fibrinogen levels among postmenopausal women, especially in subjects who were overweight. Plasma fibrinogen is a strong predictor of cardiovascular disease. Therefore, identifying new factors which independently modify plasma fibrinogen levels may be important to improve the cardiovascular risk stratification and disease prevention. Since the $3 \mathrm{C}$ case/cohort study has shown that high level of estradiol represented a new predictor of cardiovascular disease among older postmenopausal women ${ }^{37}$, it would be now of interest to investigate whether difference in plasma fibrinogen concentrations could explain part of the association of endogenous estradiol with the risk of ischemic arterial disease among older postmenopausal women. 


\section{Acknowledgements}

The Three-City Study is conducted under a partnership agreement between the Institut National de la Santé et de la Recherche Médicale (INSERM), the Victor Segalen-Bordeaux II University, and SanofiAventis. The Fondation pour la Recherche Médicale funded preparation and initiation of the study. The Three-City Study is also supported by the Caisse Nationale Maladie des Travailleurs Salarie's, Direction Générale de la Santé, MGEN, Institut de la Longévité, Conseils Régionaux of Aquitaine and Bourgogne, Fondation de France, and Ministry of Research-INSERM Programme "Cohortes et collections de données biologiques". The experiments comply with the current laws of the country in which they were performed. Biological assays regarding haemostatic and hormones parameters were supported by a grant from the Agence Nationale de la Recherche (ANR 2007-LVIE-005-01).

DISCLOSURE STATEMENT: The authors have nothing to disclose. 


\section{References}

1 Uitte de Willige, S., Standeven, K.F., Philippou, H. \& Ariens, R.A. (2009) The pleiotropic role of the fibrinogen gamma' chain in hemostasis. Blood, 114, 3994-4001.

2 Scarabin, P.Y., Aillaud, M.F., Amouyel, P., Evans, A., Luc, G., Ferrieres, J., Arveiler, D. \& Juhan-Vague, I. (1998) Associations of fibrinogen, factor VII and PAI-1 with baseline findings among 10,500 male participants in a prospective study of myocardial infarction--the PRIME Study. Prospective Epidemiological Study of Myocardial Infarction. Thromb Haemost, 80, 749-756.

3 Danesh, J., Lewington, S., Thompson, S.G., Lowe, G.D., Collins, R., Kostis, J.B., Wilson, A.C., Folsom, A.R., Wu, K., Benderly, M., Goldbourt, U., Willeit, J., Kiechl, S., Yarnell, J.W., Sweetnam, P.M., Elwood, P.C., Cushman, M., Psaty, B.M., Tracy, R.P., Tybjaerg-Hansen, A., Haverkate, F., de Maat, M.P., Fowkes, F.G., Lee, A.J., Smith, F.B., Salomaa, V., Harald, K., Rasi, R., Vahtera, E., Jousilahti, P., Pekkanen, J., D'Agostino, R., Kannel, W.B., Wilson, P.W., Tofler, G., Arocha-Pinango, C.L., Rodriguez-Larralde, A., Nagy, E., Mijares, M., Espinosa, R., Rodriquez-Roa, E., Ryder, E., Diez-Ewald, M.P., Campos, G., Fernandez, V., Torres, E., Marchioli, R., Valagussa, F., Rosengren, A., Wilhelmsen, L., Lappas, G., Eriksson, H., Cremer, P., Nagel, D., Curb, J.D., Rodriguez, B., Yano, K., Salonen, J.T., Nyyssonen, K., Tuomainen, T.P., Hedblad, B., Lind, P., Loewel, H., Koenig, W., Meade, T.W., Cooper, J.A., De Stavola, B., Knottenbelt, C., Miller, G.J., Bauer, K.A., Rosenberg, R.D., Sato, S., Kitamura, A., Naito, Y., Palosuo, T., Ducimetiere, P., Amouyel, P., Arveiler, D., Evans, A.E., Ferrieres, J., Juhan-Vague, I., Bingham, A., Schulte, H., Assmann, G., Cantin, B., Lamarche, B., Despres, J.P., Dagenais, G.R., Tunstall-Pedoe, H., Woodward, M., Ben-Shlomo, Y., Davey Smith, G., Palmieri, V., Yeh, J.L., Rudnicka, A., Ridker, P., Rodeghiero, F., Tosetto, A., Shepherd, J., Ford, I., Robertson, M., Brunner, E., Shipley, M., Feskens, E.J., Kromhout, D., Dickinson, A., Ireland, B., Juzwishin, K., Kaptoge, S., Memon, A., Sarwar, N., Walker, M., Wheeler, J., White, I. \& Wood, A. (2005) Plasma fibrinogen level and the risk of major cardiovascular diseases and nonvascular mortality: an individual participant meta-analysis. Jama, 294, 1799-1809.

4 Carcaillon, L., Gaussem, P., Ducimetiere, P., Giroud, M., Ritchie, K., Dartigues, J.F. \& Scarabin, P.Y. (2009) Elevated plasma fibrin D-dimer as a risk factor for vascular dementia: the Three-City cohort study. J Thromb Haemost, 7, 1972-1978.

5 Rossouw, J.E., Prentice, R.L., Manson, J.E., Wu, L., Barad, D., Barnabei, V.M., Ko, M., LaCroix, A.Z., Margolis, K.L. \& Stefanick, M.L. (2007) Postmenopausal hormone therapy and risk of cardiovascular disease by age and years since menopause. Jama, 297, 1465-1477.

6 Rossouw, J.E., Anderson, G.L., Prentice, R.L., LaCroix, A.Z., Kooperberg, C., Stefanick, M.L., Jackson, R.D., Beresford, S.A., Howard, B.V., Johnson, K.C., Kotchen, J.M. \& Ockene, J. (2002) Risks and benefits of estrogen plus progestin in healthy postmenopausal women: principal results From the Women's Health Initiative randomized controlled trial. Jama, 288, 321-333.

7 Anderson, G.L., Limacher, M., Assaf, A.R., Bassford, T., Beresford, S.A., Black, H., Bonds, D., Brunner, R., Brzyski, R., Caan, B., Chlebowski, R., Curb, D., Gass, M., Hays, J., Heiss, G., Hendrix, S., Howard, B.V., Hsia, J., Hubbell, A., Jackson, R., Johnson, K.C., Judd, H., Kotchen, J.M., Kuller, L., LaCroix, A.Z., Lane, D., Langer, R.D., Lasser, N., Lewis, C.E., Manson, J., Margolis, K., Ockene, J., O'Sullivan, M.J., Phillips, L., Prentice, R.L., Ritenbaugh, C., Robbins, J., Rossouw, J.E., Sarto, G., Stefanick, M.L., Van Horn, L., Wactawski-Wende, J., Wallace, R. \& Wassertheil-Smoller, S. (2004) Effects of conjugated equine estrogen in postmenopausal women with hysterectomy: the Women's Health Initiative randomized controlled trial. Jama, 291, 1701-1712.

8 Rexrode, K.M., Manson, J.E., Lee, I.M., Ridker, P.M., Sluss, P.M., Cook, N.R. \& Buring, J.E. (2003) Sex hormone levels and risk of cardiovascular events in postmenopausal women. Circulation, 108, 1688-1693.

$9 \quad$ Lee, J.S., Yaffe, K., Lui, L.Y., Cauley, J., Taylor, B., Browner, W. \& Cummings, S. (2010) Prospective study of endogenous circulating estradiol and risk of stroke in older women. Arch Neurol, 67, 195-201.

10 Chen, Y., Zeleniuch-Jacquotte, A., Arslan, A.A., Wojcik, O., Toniolo, P., Shore, R.E., Levitz, M. \& Koenig, K.L. (2011) Endogenous hormones and coronary heart disease in postmenopausal women. Atherosclerosis. 
11 Salpeter, S.R., Walsh, J.M., Ormiston, T.M., Greyber, E., Buckley, N.S. \& Salpeter, E.E. (2006) Meta-analysis: effect of hormone-replacement therapy on components of the metabolic syndrome in postmenopausal women. Diabetes Obes Metab, 8, 538-554.

12 Folsom, A.R., Golden, S.H., Boland, L.L. \& Szklo, M. (2005) Association of endogenous hormones with C-reactive protein, fibrinogen, and white blood count in post-menopausal women. Eur J Epidemiol, 20, 1015-1022.

13 Sowers, M.R., Jannausch, M., Randolph, J.F., McConnell, D., Little, R., Lasley, B., Pasternak, R., Sutton-Tyrrell, K. \& Matthews, K.A. (2005) Androgens are associated with hemostatic and inflammatory factors among women at the mid-life. J Clin Endocrinol Metab, 90, 6064-6071.

14 Sowers, M.R., Matthews, K.A., Jannausch, M., Randolph, J.F., McConnell, D., Sutton-Tyrrell, K., Little, R., Lasley, B. \& Pasternak, R. (2005) Hemostatic factors and estrogen during the menopausal transition. J Clin Endocrinol Metab, 90, 5942-5948.

15 Maturana, M.A., Breda, V., Lhullier, F. \& Spritzer, P.M. (2008) Relationship between endogenous testosterone and cardiovascular risk in early postmenopausal women. Metabolism, 57, 961-965.

16 Stirling, Y., Woolf, L., North, W.R., Seghatchian, M.J. \& Meade, T.W. (1984) Haemostasis in normal pregnancy. Thromb Haemost, 52, 176-182.

17 Bremme, K., Ostlund, E., Almqvist, I., Heinonen, K. \& Blomback, M. (1992) Enhanced thrombin generation and fibrinolytic activity in normal pregnancy and the puerperium. Obstet Gynecol, 80, 132-137.

18 Bremme, K.A. (2003) Haemostatic changes in pregnancy. Best Pract Res Clin Haematol, 16, 153-168.

19 Brenner, B. (2004) Haemostatic changes in pregnancy. Thromb Res, 114, 409-414.

20 Szecsi, P.B., Jorgensen, M., Klajnbard, A., Andersen, M.R., Colov, N.P. \& Stender, S. (2010) Haemostatic reference intervals in pregnancy. Thromb Haemost, 103, 718-727.

21 Thornton, P. \& Douglas, J. (2010) Coagulation in pregnancy. Best Pract Res Clin Obstet Gynaecol, 24, 339-352.

22 Trigg, D.E., Wood, M.G., Kouides, P.A. \& Kadir, R.A. (2011) Hormonal influences on hemostasis in women. Semin Thromb Hemost, 37, 77-86.

23 (2003) Vascular factors and risk of dementia: design of the Three-City Study and baseline characteristics of the study population. Neuroepidemiology, 22, 316-325.

24 Carcaillon, L., Alhenc-Gelas, M., Bejot, Y., Spaft, C., Ducimetiere, P., Ritchie, K., Dartigues, J.F. \& Scarabin, P.Y. (2011) Increased thrombin generation is associated with acute ischemic stroke but not with coronary heart disease in the elderly: the Three-City cohort study. Arterioscler Thromb Vasc Biol, 31, 1445-1451.

25 Raven, G., de Jong, F.H., Kaufman, J.M. \& de Ronde, W. (2006) In men, peripheral estradiol levels directly reflect the action of estrogens at the hypothalamo-pituitary level to inhibit gonadotropin secretion. J Clin Endocrinol Metab, 91, 3324-3328.

26 Larson, M.G. (2006) Descriptive statistics and graphical displays. Circulation, 114, 76-81.

27 Harnett, M.J., Bhavani-Shankar, K., Datta, S. \& Tsen, L.C. (2002) In vitro fertilizationinduced alterations in coagulation and fibrinolysis as measured by thromboelastography. Anesth Analg, 95, 1063-1066, table of contents.

28 Ricci, G., Cerneca, F., Simeone, R., Pozzobon, C., Guarnieri, S., Sartore, A., Pregazzi, R. \& Guaschino, S. (2004) Impact of highly purified urinary FSH and recombinant FSH on haemostasis: an open-label, randomized, controlled trial. Hum Reprod, 19, 838-848.

29 Muller-Berghaus, G., Moeller, R.M. \& Mahn, I. (1978) Fibrinogen turnover in pregnant rabbits during the first and last thirds of gestation. Am J Obstet Gynecol, 131, 655-660.

30 Stork, S., Bots, M.L., Grobbee, D.E. \& van der Schouw, Y.T. (2008) Endogenous sex hormones and C-reactive protein in healthy postmenopausal women. J Intern Med, 264, 245-253.

31 Maggio, M., Ceda, G.P., Lauretani, F., Bandinelli, S., Corsi, A.M., Giallauria, F., Guralnik, J.M., Zuliani, G., Cattabiani, C., Parrino, S., Ablondi, F., Dall'aglio, E., Ceresini, G., Basaria, S. \& Ferrucci, L. (2011) SHBG, sex hormones, and inflammatory markers in older women. J Clin Endocrinol Metab, 96, 1053-1059.

32 Maury, E. \& Brichard, S.M. (2010) Adipokine dysregulation, adipose tissue inflammation and metabolic syndrome. Mol Cell Endocrinol, 314, 1-16. 
33 Alessi, M.C., Poggi, M. \& Juhan-Vague, I. (2007) Plasminogen activator inhibitor-1, adipose tissue and insulin resistance. Curr Opin Lipidol, 18, 240-245.

34 Baglietto, L., English, D.R., Hopper, J.L., MacInnis, R.J., Morris, H.A., Tilley, W.D., Krishnan, K. \& Giles, G.G. (2009) Circulating steroid hormone concentrations in postmenopausal women in relation to body size and composition. Breast Cancer Res Treat, 115, 171-179.

35 Borissoff, J.I., Spronk, H.M. \& ten Cate, H. (2011) The hemostatic system as a modulator of atherosclerosis. N Engl J Med, 364, 1746-1760.

36 Stanczyk, F.Z., Jurow, J. \& Hsing, A.W. (2010) Limitations of direct immunoassays for measuring circulating estradiol levels in postmenopausal women and men in epidemiologic studies. Cancer Epidemiol Biomarkers Prev, 19, 903-906.

37 Scarabin, V., Canonico, M., Brailly-Tabard, S., Trabado, S., Ducimetiere, P., Giroud, M., Ryan, J., Helmer, C., Plu-Bureau, G., Guiochon-Mantel, A. \& Scarabin, P.Y. (2012) High level of plasma estradiol as a new predictor of ischemic arterial disease in older postmenopausal women: The Three-City cohort study. Journal of the American Heart Association, in press. 


\section{Tables and figure}

Table 1. Baseline characteristics of the women selected within the subcohort sample $(n=602)$

Table 2. Association of fibrinogen with total E2, total T and SHBG assessed in linear regression models

Figure 1. Adjusted means of fibrinogen according to the tertiles of total estradiol by overweight status 
Table 1. Baseline characteristics of the women selected within the subcohort sample in the 3C Study $(n=602)$

\begin{tabular}{ll}
\hline Characteristics & Value \\
\hline Age (years) & $74.8(5.5)$ \\
Body-mass index $\left(\mathrm{kg} / \mathrm{m}^{2}\right)$ & $25.6(4.6)$ \\
Body-mass index $\geq 25 \mathrm{~kg} / \mathrm{m}^{2}$ & $287(48.2)$
\end{tabular}

Education

Less than grade school $229(38.0)$

Grade school or high school $\quad 187$ (31.1)

High school validated or university $186(30.9)$

Natural menopause $\quad 474(91.2)$

Smoking status

Never $\quad 489(81.2)$

Past $\quad 87(14.5)$

Current 26(4.3)

$\begin{array}{ll}\text { Hypertension } & 467(77.6)\end{array}$

Glycemia

Normal glycemia $\quad 534(88.8)$

High glycemia 21 (3.5)

Diabetes $\quad 46(7.7)$

Hypercholesterolemia 382 (63.5)

Prevalent disorder*

Coronary heart disease $\quad 53(8.8)$

Stroke 25( 4.2)

Dementia $13(2.2)$

Biological parameters

$\begin{array}{ll}\text { Total E2 }(\mathrm{pg} / \mathrm{ml}) & 5.29(3.54-8.32) \\ \text { Total T }(\mathrm{ng} / \mathrm{ml}) & 0.28(0.20-0.45) \\ \text { SHBG }(\mathrm{nmol} / \mathrm{l}) & 26.3(18.2-38.1) \\ \text { Fibrinogen }(\mathrm{g} / \mathrm{l}) & 3.42(0.65)\end{array}$

Data are given as $n(\%)$ or arithmetic means (SD) except for steroid sex hormones expressed as geometric means (interquartile range)

* 7 subjects presentend more than one prevalent disorder

E2: estradiol

$\mathrm{T}$ : testosterone 
Table 2. Association of fibrinogen with total E2, total T and SHBG assessed in linear regression models in the $3 \mathrm{C}$ study

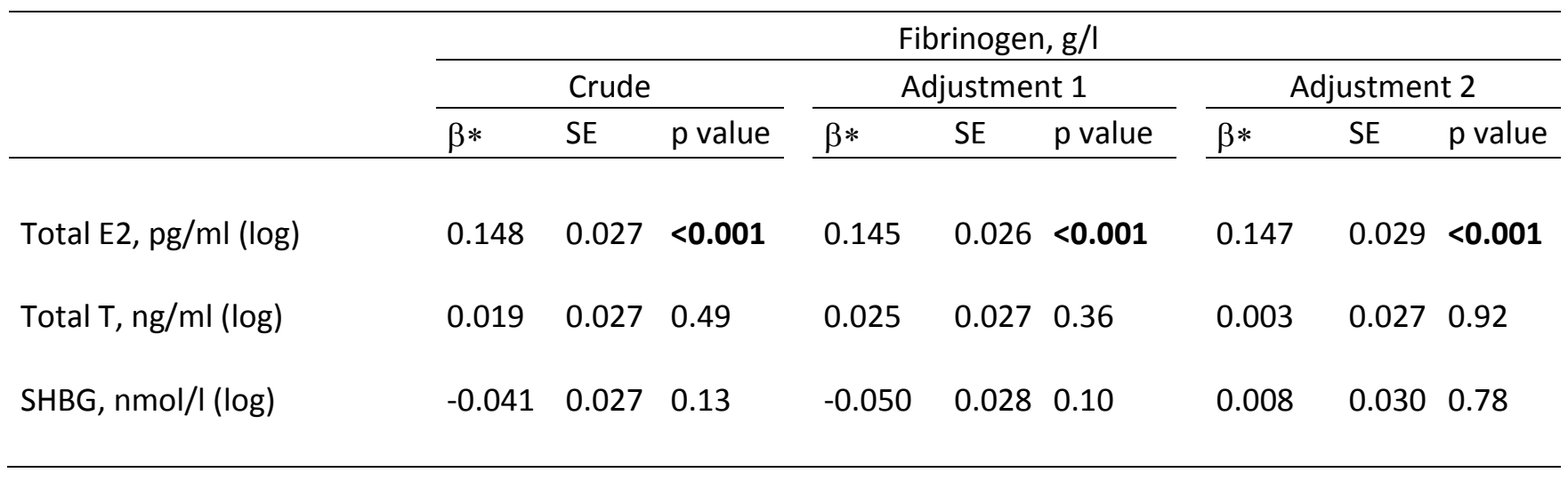

E2: estradiol

$\mathrm{T}$ : Testosterone

Adjustment 1: adjustment for center, age, hypertension, diabetes, hypercholesterolemia and smoking status

Adjustement 2: adjustment for center, age, hypertension, diabetes, hypercholesterolemia, smoking status and other steroid sex hormones

* beta-coefficient of fibrinogen unit for 1 SD increment in the log-distribution of steroid sex hormones and SHBG 
Figure 1. Adjusted means* of fibrinogen according to the tertiles of total estradiol by overweight status

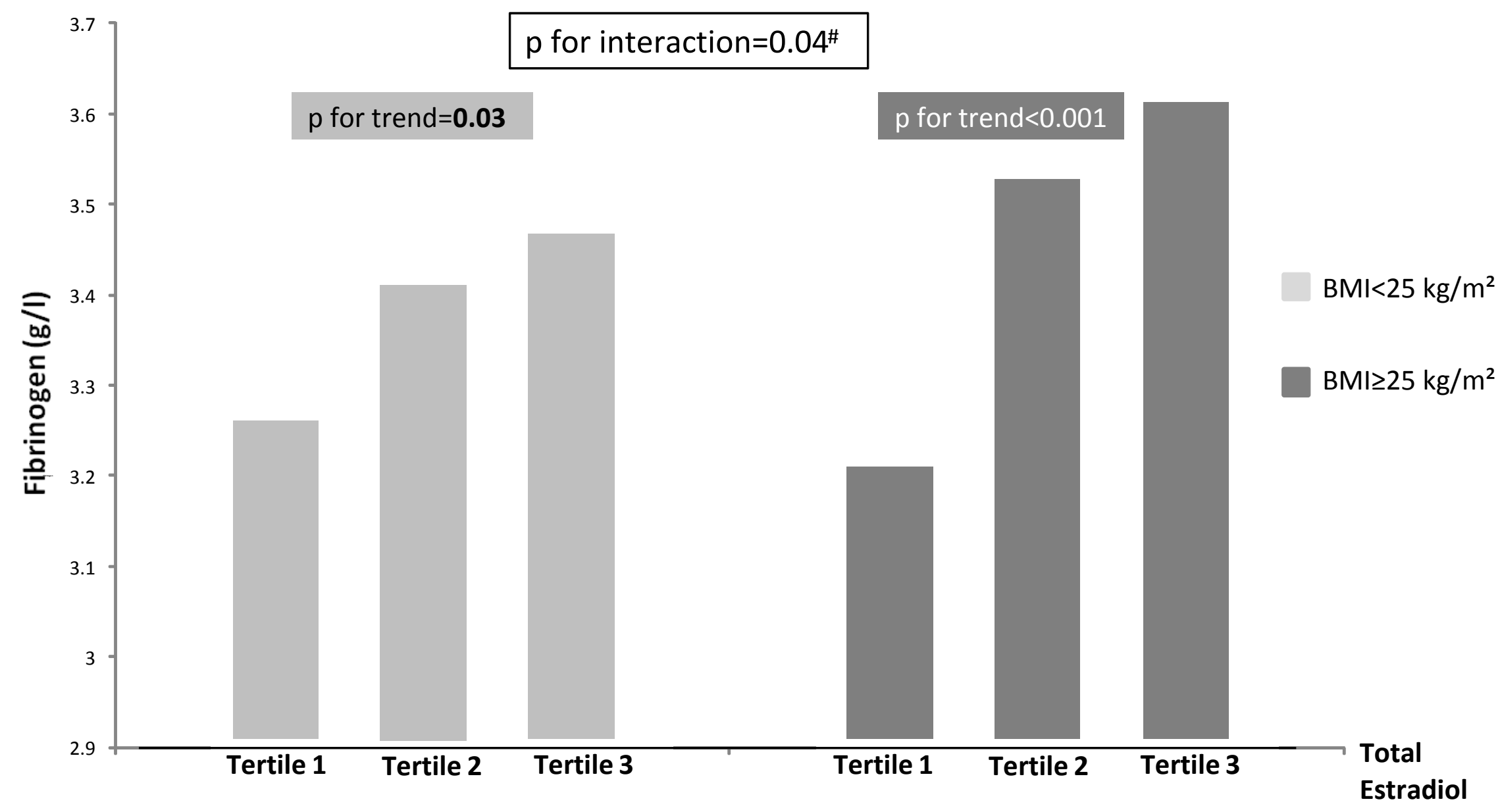

* Adjusted for center, age, BMI, hypertension, diabetes, hypercholesterolemia and smoking status

\# Total estradiol and BMI were used as continuous variables 